This is the author's final, peer-reviewed manuscript as accepted for publication. The publisher-formatted version may be available through the publisher's web site or your institution's library.

\title{
Rotary ultrasonic machining of carbon fiber reinforced plastic composites: using cutting fluid versus cold air as coolant
}

W. L. Cong, Q. Feng, Z. J. Pei, T. W. Deines, C. Treadwell

\section{How to cite this manuscript}

If you make reference to this version of the manuscript, use the following information:

Cong, W. L., Feng, Q., Pei, Z. J., Deines, T. W., \& Treadwell, C. (2012). Rotary ultrasonic machining of carbon fiber reinforced plastic composites: Using cutting fluid versus cold air as coolant. Retrieved from http://krex.ksu.edu

\section{Published Version Information}

Citation: Cong, W. L., Feng, Q., Pei, Z. J., Deines, T. W., \& Treadwell, C. (2012). Rotary ultrasonic machining of carbon fiber reinforced plastic composites: Using cutting fluid versus cold air as coolant. Journal of Composite Materials, 46(14), 1745-1753.

Copyright: @ The Author(s) 2011

Digital Object Identifier (DOI): doi:10.1177/0021998311424625

Publisher's Link: http://jcm.sagepub.com/content/46/14/1745

This item was retrieved from the K-State Research Exchange (K-REx), the institutional repository of Kansas State University. K-REx is available at http://krex.ksu.edu 


\title{
Rotary ultrasonic machining of carbon fiber reinforced plastic composites: using cutting fluid versus cold air as coolant
}

\author{
W.L. Cong, Q. Feng, Z.J. Pei ${ }^{*}$, T.W. Deines \\ Department of Industrial and Manufacturing Systems Engineering, \\ Kansas State University, \\ Manhattan, KS 66506, USA \\ C. Treadwell \\ Sonic-Mill, 7500 Bluewater Road NW, \\ Albuquerque, NM 87121, USA
}

\section{Key words:}

Carbon fiber reinforced plastic composite, Cold air, Coolant, Cutting fluid, Drilling, Rotary ultrasonic machining.

\begin{abstract}
:
Drilling is involved in many applications of carbon fiber reinforced plastic (CFRP) composites. Rotary ultrasonic machining (RUM) has been successfully employed to drill holes in CFRP using either cutting fluid or cold air as coolant. However, there are no reported studies to compare the results in RUM of CFRP using these two types of coolant. This paper, for the first
\end{abstract}

\footnotetext{
* Corresponding author. Tel.: +1 785532 3436; fax: +1 7855323738.

E-mail address: zpei@ksu.edu (Z.J. Pei).
} 
time, presents an experimental study to compare cutting force, torque, surface roughness, burning of machined surface, and tool wear in RUM of CFRP using these two types of coolant. This study will result in knowledge about machining conditions under which it is feasible to use cold air instead of cutting fluid and differences in machined hole quality produced using cold air versus cutting fluid.

\section{Introduction}

CFRP composites have high strength to weight ratios [Davim and Reis, 2003, Lambert, 1987; Sadat, 1995; Guu et al., 2001], low density [Chung, 2010], superior stiffness to weight ratios [Davim and Reis, 2003; Guu et al., 2001], strong tailorability [Chung, 2010], high damping ability [Chung, 2010], low thermal expansion [Mallick, 1997; Schwartz, 1992], high service

temperatures [Guu et al., 2001], and high chemical (corrosion) resistance [Chung, 2010]. These properties cannot be obtained from conventional metals such as steel and aluminum [Mallick, 1997; Schwartz, 1992]. CFRP composites are attractive for many applications due to these superior properties. They are used in many types of structures including aircraft, spacecraft, automobile, ship, bridge, athletic equipment, and leisure goods. They are also employed in engine blades, power transmission shafts, machine spindles, robot arms, pressure vessels, and chemical containers [Park et al., 1995; Ruegg and Habermeier, 1981; Gay et al., 2003; Guu et al., 2001; Arul et al., 2006; Sadat, 1995]. 
Many applications of carbon fiber reinforced plastic (CFRP) composites require machining [Enemuoh et al., 2001; Chung, 2010; Gay et al., 2003], including milling [Hashmi et al., 2009; De Lacalle et al., 2009] and drilling. Twist drilling is widely used to produce holes in CFRP [Rubio et al., 2008; Gaitonde et al., 2008; Ramulu et al. 2001; Tsao and Hocheng, 2004; 2005; 2007; Davim and Reis, 2003; Hocheng et al., 2003; 2006]. Rotary ultrasonic machining (RUM) has also been successfully used to drill holes in CFRP [Li et al., 2007; Cong et al., 2011ab]. RUM is a hybrid machining process that combines material removal mechanisms of diamond grinding and ultrasonic machining. A rotating core drill with metal-bonded diamond abrasives vibrates ultrasonically in its axial direction and feeds towards the workpiece. Coolant (cutting fluid or cold air) goes through the core of the drill to wash out swarfs and keeps cutting temperature low. Compared with twist drilling, RUM has many advantages, such as smaller cutting force, lower surface roughness, less tool wear, and less delamination. An experimental investigation to compare twist drilling and RUM using the same workpiece material and similar machining conditions has been conducted by the authors. Results of the investigation will be published in a separate paper.

Cutting fluids help to remove the heat generated during machining; to achieve better tool life, surface finish, and dimensional tolerance; to prevent the formation of built-up edge; and to facilitate the transportation of chips [Sreejith and Ngoi, 2000]. However, cutting fluids also have 
several disadvantages. First, deployment of cutting fluids counts for about $7-17 \%$ of the total cost of machining. As a comparison, costs of tool only account for approximately $2-4 \%$ [Klock and Eisenblatter, 1997]. Moreover, treatment of waste cutting fluids also has considerable costs. Second, one of the major concerns is the health and environment hazard associated with cutting fluids [Arumugam et al., 2006].

Dry machining (machining without direct contact between coolant fluid and cutting zone) can avoid the problems related to cutting fluids. However, dry machining can potentially cause burning of machined surface, more friction and adhesion between tool and workpiece, reduction of tool life, and high surface roughness [Liu and Hu, 1997; Sreejith and Ngoi, 2000; Nguyen and Zhang, 2003].

Reported experimental investigations [Li et al., 2007; Cong et al., 2011ab] on RUM of CFRP employed either cutting fluid or cold air as coolant. However, there are no reported studies to compare the results in RUM of CFRP using these two types of coolant. This paper, for the first time, presents an experimental study to compare cutting force, torque, surface roughness, burning of machined surface, and tool wear in RUM of CFRP using these two types of coolant. 


\section{Experimental conditions and measurement procedures}

The workpiece size was $200 \mathrm{~mm} \times 150 \mathrm{~mm} \times 16 \mathrm{~mm}$. The workpiece material was carbon

fiber reinforced plastic (CFRP) composites. It was composed of carbon fibers and epoxy resin. Plain woven fabric of carbon fibers had an orientation of 0/90 degrees. The carbon fiber yarn in the woven fabric had a thickness of $0.2 \mathrm{~mm}$ and a width of $2.5 \mathrm{~mm}$. The workpiece contained 42 layers of carbon fibers. Workpiece material properties are listed in Table 1.

Drilling experiments were performed on a rotary ultrasonic machine (Series 10, Sonic-Mill, Albuquerque, NM, USA). The experimental set-up is schematically illustrated in Figure 1. It mainly consisted of an ultrasonic spindle system, a data acquisition system, and a cooling system. The ultrasonic spindle system was comprised of an ultrasonic spindle, a power supply, and a motor speed controller. The power supply converted conventional line voltage to $20 \mathrm{kHz}$ electrical energy. This high-frequency electrical energy was provided to a piezoelectric converter that changed high-frequency electrical energy into mechanical vibration. The ultrasonic vibration was amplified and transmitted to the cutting tool. This caused the cutting tool to vibrate at the frequency of $20 \mathrm{kHz}$. The amplitude of ultrasonic vibration could be adjusted by changing the setting of output control of the power supply. The motor attached atop the ultrasonic spindle supplied the rotational motion of the tool and different speeds could be obtained by adjusting the motor speed controller. The data acquisition system, including dynamometer, charge amplifier, 
A/D convertor, and computer with software, was used for measurement of cutting force and torque. More details about this system will be described in Section 2.4 (measurement procedures). There were two separate cooling systems: cutting fluid cooling system and cold air cooling system. The cutting fluid cooling system was comprised of pump, coolant tank, pressure regulator, flow rate and pressure gauges, and valves. The cold air cooling system included air compressor, oil and water filter, pressure regulator and valve, vortex tube, and pressure meters. The cooling system provided coolant (cutting fluid or cold air) to the spindle and the interface of machining.

In this study, the cold air was generated by a vortex tube (VT). The VT separated a stream of compressed air into a hot and a cool branch. Hot air came out of one end of the tube and cold air out of the other [Ahlborn et al., 1994; Liu and Chou, 2005 \& 2007; AiRTX 2010; Hilsch, 1947; Cong et al., 2008]. The cutting fluid (Quakercool 6010, Murdock Industrial Supply Co., Wichita, KS, USA) was of water-soluble type.

Metal-bonded diamond core drills (NBR Diamond Tool Corp., LaGrangeville, NY, USA) were used. The outer and inner diameters (OD and ID) of the drills were $9.54 \mathrm{~mm}$ and $7.82 \mathrm{~mm}$, respectively, and the tuning length was $45 \mathrm{~mm}$. The diamond abrasives had mesh size of 60/80 and concentration of 100 . The metal bond was of B type. 
Following input variables were varied in the experiments:

- Spindle speed: Rotational speed of core drill;

- Feedrate: Feedrate of core drill;

- Ultrasonic power: Percentage of power from ultrasonic power supply (higher ultrasonic power would produce higher ultrasonic vibration amplitude);

- Coolant type: Cutting fluid or cold air.

The pressure and flow rate for both cutting fluid and cold air were kept the same at 40 psi and $1.5 \mathrm{lpm}$, respectively. The input variables and their values are shown in Table 2. Four holes were drilled under each machining condition to study cutting force, torque, surface roughness, and burning of machined surface.

A dynamometer (Model 9272, Kistler Inc., Switzerland) was used to measure the cutting force and torque. The electrical signals from the dynamometer were amplified by a charge amplifier (Model 5070A, Kistler Inc., Switzerland) and transformed into digital signals by an A/D converter. After being processed by a signal conditioner, the digital signals were saved on a computer by a data acquisition card (PC-CARD-DAS16/16, Measurement Computing Corporation, Norton, MA, USA) with the help of DynoWare software (Type 2815A, Kistler Inc., Switzerland). The sampling rate was set at $20 \mathrm{~Hz}$. The maximum cutting force in the tool axial direction during the entire period of time to drill a hole was used as the cutting force for drilling the hole. Similarly, the maximum torque was used as the torque for drilling the hole. 
Surface roughness was measured on the cylindrical surfaces of machined holes along the axial direction. A surface profilometer (Surftest-402, Mitutoyo Corporation, Kanagawa, Japan) was used with the test range being set as $4 \mathrm{~mm}$ and the cut-off length as $0.8 \mathrm{~mm}$. The surface roughness in this study was characterized by $\mathrm{Ra}$, average surface roughness. Roughness was measured at two locations of the hole: entrance and exit. At each location, four measurements were performed with $90^{\circ}$ between two adjacent measurements. Each measurement was repeated four times. Therefore, at each location, there were eight measured Ra values. The average of these eight Ra values was used as the Ra value for the location.

During machining, the epoxy matrix could be burned under certain conditions due to machining-induced heat. Burning ratio $\left(=\frac{\text { Burning area on machined hole surface }}{\text { Total area of machined hole surface }}\right)$ was used to describe the severity of burning on the machined hole surface. In the paper, burning ratio was estimated by the ratio between the number of fiber layers that had burning and the number of fiber layers that had no burning.

Tool wear was evaluated using the weight loss of the tool (using the weight of the tool prior to the tests as the reference). Before weight measurement, the tool was cleaned (using methanol and acetone) and dried (using a hand dryer). The tool weight was measured by a high-accuracy 
scale (Model APX-200, Denver Instrument, Denver, CO, USA).

\section{Experimental results}

\subsection{Results on cutting force}

Figure 2 shows a comparison of cutting force between the two types of coolant under different settings of ultrasonic power. In Figure 2 (as well as Figures $3-11$ ), each data point is the average value for the four holes drilled under that condition. Error bars represent the minimum and maximum values among the four holes. It can be seen that, for both types of coolant, cutting force decreased with the increase of ultrasonic power. When ultrasonic power increased from $0 \%$ to $80 \%$, the decrease of cutting force was about $20 \mathrm{~N}$ for both types of coolant. Using cold air resulted in larger cutting force. The difference in cutting force between these two types of coolant did not change much when ultrasonic power changed. Cold air did not have the lubricating effect that cutting fluid had, resulting in larger cutting force.

A comparison of cutting force between the two types of coolant under different settings of tool rotation speed is shown in Figure 3. Cutting force decreased with the increase of tool rotation speed for both types of coolant. When tool rotation speed was between 1000 and 3000 rpm, using cold air led to larger cutting force. When tool rotation speed was between 4000 and 
$5000 \mathrm{rpm}$, cutting force was about the same for both types of coolant. Cutting force in RUM of CFRP (as well as titanium, stainless steel, alumina, and silicon carbide) was determined by the interaction force between diamond grains on the drill end surface and the workpiece material. This interaction force was affected by the penetration depth of diamond grains into the workpiece material. As tool rotation speed increased, the penetration depth of diamond grains into the workpiece material would decrease (since the feedrate was kept the same). This would reduce the interaction force between diamond grains and the workpiece material, hence reducing cutting force.

A comparison of cutting force between the two types of coolant under different settings of feedrate is shown in Figure 4. With the increase of feedrate, cutting force increased for both types of coolant. At some feedrate settings (such as $0.1,0.7$, and $0.8 \mathrm{~mm} / \mathrm{s}$ ), cutting force was about the same for both types of coolant. At other feedrate settings (from 0.2 to $0.6 \mathrm{~mm} / \mathrm{s}$ ), using cold air resulted in larger cutting force. As feedrate increased, the penetration depth of diamond grains into the workpiece material would increase. This would increase the interaction force between diamond grains and the workpiece material, hence increasing cutting force.

\subsection{Results on torque}

Figure 5 shows a torque comparison between the two types of coolant under different 
settings of ultrasonic power. Torque decreased with the increase of ultrasonic power for both types of coolant. The torque was about $0.5 \mathrm{~N} \cdot \mathrm{m}$ for both types of coolant when ultrasonic power was 0 (without ultrasonic vibration). When ultrasonic power was between $20 \%$ and $80 \%$, using cold air had larger torque than using cutting fluid. The trends of cutting force and torque as ultrasonic power increased were the same. The reason for larger torque with cold air was similar to that for larger cutting force with cold air.

A comparison of torque between the two types of coolant under different settings of tool rotation speed is shown in Figure 6. With the increase of tool rotation speed, torque decreased for both types of coolant. Using cold air led to larger torque than using cutting fluid. When tool rotation speed was $1000 \mathrm{rpm}$, using cold air had much larger torque $(1.4 \mathrm{~N} \cdot \mathrm{m})$ than using cutting fluid $(0.45 \mathrm{~N} \cdot \mathrm{m})$. When tool rotation speed was between 2000 and $5000 \mathrm{rpm}$, using cold air led to slightly larger torque than using cutting fluid. This trend was similar to that of cutting force.

Figure 7 shows a torque comparison between the two types of coolant under different settings of feedrate. It can be seen that torque increased with the increase of feedrate for both types of coolant. Using cold air led to larger torque than using cutting fluid. When feedrate increased from 0.1 to $0.6 \mathrm{~mm} / \mathrm{s}$, the increase of torque was slow for both types of coolant. However, when feedrate increased from 0.6 to $0.8 \mathrm{~mm} / \mathrm{s}$, the increase of torque became fast for both types of coolant. Again, cutting force and torque had a similar trend as feedrate increased. 


\subsection{Results on surface roughness}

A comparison of surface roughness between the two types of coolant under different settings of ultrasonic power is shown in Figure 8. As the entrance location, as shown in Figure 8(a), with the increase of ultrasonic power, surface roughness increased when using cold air, but did not change much when using cutting fluid. Using cutting fluid led to lower surface roughness at all settings of ultrasonic power. At the exit location, as shown in Figure 8(b), surface roughness and ultrasonic power did not have monotonous relationship for both types of coolant. Surface roughness when using cutting fluid was lower than that when using cold air at all settings of ultrasonic power. The lubricating effect of cutting fluid would result in lower surface roughness.

Figure 9 shows a comparison of surface roughness between the two types of coolant under different settings of tool rotation speed. Surface roughness decreased as tool rotation speed increased for both types of coolant. The reason could be that, as tool rotation speed increased, the linear cutting speed increased. At all settings of tool rotation speed, surface roughness when using cutting fluid was lower than that when using cold air. When tool rotation speed was between 1000 and $2000 \mathrm{rpm}$, using cold air led to higher surface roughness. This was because severe surface burning happened in RUM of CFRP using cold air when tool rotation was low (1000 or $2000 \mathrm{rpm})$. When tool rotation speed was between 3000 and $5000 \mathrm{rpm}$, surface 
roughness had similar values for both types of coolant.

Figure 10 shows a comparison of surface roughness between the two types of coolant under different settings of feedrate. For both types of coolant, surface roughness increased with the increase of feedrate. At all settings of feedrate, surface roughness when using cold air was higher than that when using cutting fluid. With the increase of feedrate, the difference in surface roughness between the two types of coolant became larger.

\subsection{Results on burning of machined surface}

Burning of machined surface did not occur when using cutting fluid under any of the test conditions. In contrast, burning occurred when using cold air under some conditions. Tables 3-5 show the results on burning ratio when using cold air.

Table 3 shows effects of ultrasonic power on burning ratio. When feedrate was $0.1 \mathrm{~mm} / \mathrm{s}$, higher ultrasonic power $(80 \%)$ caused burning of machined surface. When feedrate was 0.5 $\mathrm{mm} / \mathrm{s}$, burning did not occur no matter what ultrasonic power was. Table 4 shows effects of tool rotation speed on burning ratio. When feedrate was $0.5 \mathrm{~mm} / \mathrm{s}$, burning ratio became higher as tool rotation speed decreased (to 1000 or $2000 \mathrm{rpm}$ ). When feedrate was $0.1 \mathrm{~mm} / \mathrm{s}$, burning did 
not occur no matter what tool rotation speed was. Table 5 shows effects of feedrate on burning ratio. Burning ratio became higher when feedrate was too high $(0.7$ and $0.8 \mathrm{~mm} / \mathrm{s})$.

\subsection{Results on tool wear}

Figure 11 compares tool wear (i.e. cumulative tool weight loss) between the two types of coolant. For the first ten holes, both types of coolant had similar tool wear. After ten holes, as more holes were drilled, tool wear increased steadily when using cold air, but did not change much when using cutting fluid. Differences in tool weight loss between the two types of coolant increased as more holes were drilled. After 30 holes were drilled, the difference was around 8 mg.

\section{Conclusions}

This paper reported a comparison study on rotary ultrasonic machining of CFRP using two types of coolant: cutting fluid versus cold air. Cutting force, torque, surface roughness, burning of machined surface, and tool wear have been compared under different settings of machining variables. The following settings of conclusions are drawn from this study:

(a) Using cold air led to larger cutting force and torque than using cutting fluid under most conditions. However, under some conditions, cutting force or torque values were about the same for both types of coolant. 
(b) Surface roughness using cold air was usually higher than that using cutting fluid.

(c) Using cold air, higher ultrasonic power, lower tool rotation speed, and higher feedrate could lead to more severe burning of machined surface. In contrast, no burning of machined surface was observed using cutting fluid.

(d) Tool wear when using cold air was more severe than that when using cutting fluid.

\section{Acknowledgements}

The work was supported by the National Science Foundation through award CMMI-0900462. The authors gratefully extend their acknowledgements to Mr. Bruno Renzi at N.B.R. Diamond Tool Corp. for supplying the diamond core drills. Thanks also go to Mr. Eric Zinke and Mr. Jeffrey Wilbert, undergraduate students in the Department of Industrial and Manufacturing Systems Engineering, Kansas State University, for their help during this study.

\section{References}

[1] Ahlborn, B., Keller, J.U., Staudt, R., Treitz, G., and Rebhan, E., 1994, Limits of temperature separation in a vortex tube, Journal of Physics D: Applied Physics, 27(3), pp. 480-488.

[2] AiRTX, 2010, How Vortex Tubes Work, Company Web site, available at: http://www.airtxinternational.com/vortex-tubes/. 
[3] Arul, S., Vijayaraghavan, L., Malhotra, S.K., and Krishnamurthy, R., 2006, The effect of vibratory drilling on hole quality in polymeric composites, International Journal of Machine Tools and Manufacture, 46(3-4), pp. 252-259.

[4] Arumugam, P.U., Malshe, A.P., and Batzer, S.A., 2006, Dry machining of aluminum-silicon alloy using polished CVD diamond-coated cutting tools inserts, Surface and Coating Technology, 200(11), pp. 3399-3403.

[5] Chung, D.D.L., 2010, Composite Materials Science and Applications, Second edition, Springer-Verlag London Ltd., London, UK.

[6] Cong, W.L., and Pei, Z.J., 2008, Dry machining using vortex-tube generated cold air as coolant: a literature review, Proceedings of the ASME International Manufacturing Science and Engineering Conference, October 7-10, Evanston, IL, USA.

[7] Cong, W.L., Feng, Q., Pei, Z.J., Deines, T., and Treadwell, C., 2011a, Dry machining of carbon fiber reinforced plastic composite by rotary ultrasonic machining: effects of machining variables, Proceedings of the ASME 2011 International Manufacturing Science and Engineering Conference, June 13-17, Corvallis, OR, USA.

[8] Cong, W.L., Feng, Q., Pei, Z.J., Deines, T., and Treadwell, C., 2011b, Rotary ultrasonic machining of CFRP using cold air as coolant: feasible regions, accepted to appear in Journal of Reinforced Plastics and Composites.

[9] Davim, J.P., and Reis, P., 2003, Drilling carbon fiber reinforced plastics manufactured by autoclave-experimental and statistical study, Materials and Design, 24(5), pp. 315-324. 
[10] De Lacalle, L.N.L., Lamikiz, A., Campa, F.J., Valdivielso, A.F., and Etxeberria, I., 2009, Design and test of a multitooth tool for CFRP milling, Journal of Composite Materials, 43(26), pp. 3275-3290.

[11] Enemuoh, E.U., El-Gizawy, A.S., and Okafor, A.C., 2001, An approach for development of damage-free drilling of carbon fiber reinforced thermosets, International Journal of Machine Tools and Manufacture, 41(12), pp. 1795-1814.

[12] Gaitonde, V.N., Karnik, S.R., Rubio, J.C., Correia, A.E., Abrao, A.M., and Davim, J.P., 2008, Analysis of parametric influence on delamination in high-speed drilling of carbon fiber reinforced plastic composites, Journal of Materials Processing Technology, 203(1-3), pp. 431-438.

[13] Gay, D., Hoa, S.V., and Tsai, S.W., 2003, Composite Materials Design and Applications, CRC Press, Boca Raton, FL, USA.

[14] Guu, Y.H., Hocheng, H., Tai, N.H., and Liu, S.Y., 2001, Effect of electrical discharge machining on the characteristics of carbon fiber reinforced carbon composites, Journal of Materials Science, 36(8), pp. 2037-2043.

[15] Hashmi, M.S.J., Yilbas B.S., and Naher, S., 2009, Milling of carbon fiber reinforced plastics, Advanced Materials Research, 83-86, pp. 49-55.

[16] Hilsch R., 1947, The use of the expansion of gases in a centrifugal field as cooling process, The Review of Scientific Instruments, 18(2), pp. 108-1113.

[17] Hocheng, H., and Tsao, C.C., 2003, Comprehensive analysis of delamination in drilling of 
composite materials with various drill bits, Journal of Materials Processing Technology, 140(1-3), pp. 335-339.

[18] Hocheng, H., and Tsao, C.C., 2006, Effect of special drill bits on drilling-induced delamination of composite materials, Journal of Machine Tools and Manufacture, 46(12-13), pp. 1403-1416.

[19] Klock, F., and Eisenblatter, G., 1997, Dry cutting, Annals of the CIRP, 46(2), pp. 519-526.

[20] Lambert, B.K., 1987, Cutting and drilling of composite materials, The Carbide and Tool Journal, 19(5), pp. 31-34.

[21] Li, Z.C., Pei, Z.J., Sisco, T., Micale, A.C., and Treadwell, C., 2007, Experimental study on rotary ultrasonic machining of graphite/epoxy panel, Proceedings of the ASPE 2007 Spring Topical Meeting on Vibration Assisted Machining Technology, April 16-17, Chapel Hill, NC, USA, pp. 52-57.

[22] Liu, C.X., and Hu, R.S., 1997, Cooling air from vortex tube applied to tool cooling, Manufacturing Technology and Machine Tool, 1, pp. 30-31. (In Chinese).

[23] Liu, J., and Chou, Y. K., 2005, Vortex-tube cooling for tool wear reduction in A390 dry machining, World Tribology Congress III, September 12-16, Washington D.C., USA, pp. 837-838.

[24] Liu, J., and Chou, Y.K., 2007, On temperatures and tool wear in machining hypereutectic Al-Si alloys with vortex-tube cooling, International Journal of Machine Tools and Manufacture, 47(3-4), pp. 635-645. 
[25] Mallick, P.K., 1997, Composite Engineering Handbook, Marcel Dekker Inc., New York, NY, USA.

[26] Nguyen, T., and Zhang, L.C., 2003, An assessment of the applicability of cold air and oil mist in surface grinding, Journal of Materials Processing Technology, 140(1-3), pp. 224-230.

[27] Park, K.Y., Choi, J.H., and Lee, D.G., 1995, Delamination-free and high efficiency drilling of carbon fiber reinforced plastics, Journal of Composite Materials, 29(15), pp. 1988-2002.

[28] Ruegg, C.H., and Habermeier, J., 1981, Composite propeller shafts: design and optimization, Automotive Engineer, 6(3), pp. 13-15.

[29] Rubio, J.C., Abrao, A.M., Faria, P.E., Correia, A.E., and Davim, J.P., 2008, Delamination in high speed drilling of carbon fiber reinforced plastic (CFRP), Journal of Composite Materials, 42(15), pp. 1523-1532.

[30] Ramulu M., Branson T., and Kim D., 2001, A study on the drilling of composite and titanium stacks, Composite Structure, 54(1), pp. 67-77.

[31] Sadat, A.B., 1995, Delamination and other types of damage of graphite/epoxy composite caused by machining, American Society of Mechanical Engineers, Applied Mechanics Division, 208, pp. 41-52.

[32] Schwartz, M.M., 1992, Composite Materials Handbook, Second edition, McGraw-Hill, Columbus, OH, USA.

[33] Sreejith, P.S., and Ngoi, B.K.A., 2000, Dry machining: machining of the future, Journal of 
Materials Processing Technology, 101(1-3), pp. 287-291.

[34] Tsao, C.C., and Hocheng, H., 2004, Taguchi analysis of delamination associated with various drill bits in drilling of composite material, International Journal of Machine Tools and Manufacture, 44(10), pp. 1085-1090.

[35] Tsao, C.C., and Hocheng, H., 2005, Effect of eccentricity of twist drill and candle stick drill on delamination in drilling composite materials, International Journal of Machine Tools and Manufacture, 45(2), pp. 125-130.

[36] Tsao, C.C., and Hocheng, H., 2007, Effect of tool wear on delamination in drilling composite materials, International Journal of Mechanical Sciences, 49(8), pp. 983-988. 


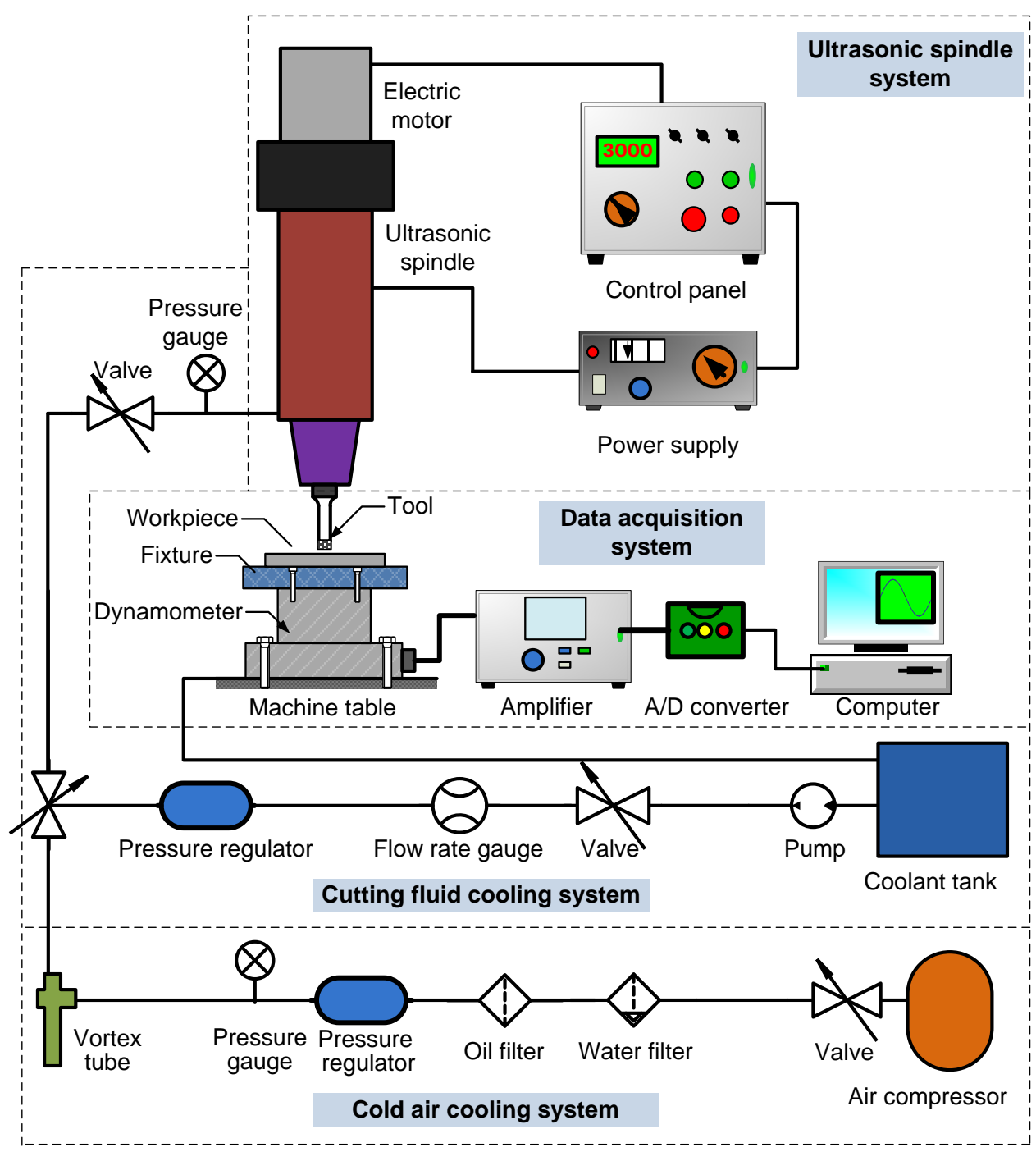

Figure 1 Experimental set-up. 


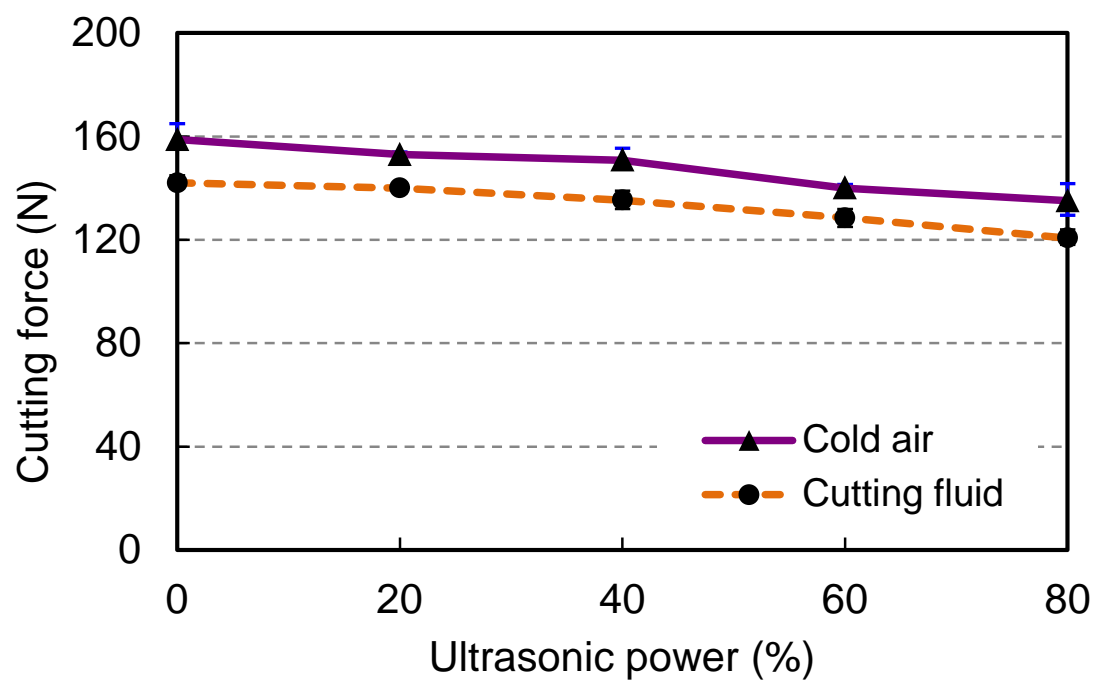

Tool rotation speed $=3000 \mathrm{rpm}$

Feedrate $=0.5 \mathrm{~mm} / \mathrm{s}$

Figure 2 Comparison of cutting force under different settings of ultrasonic power. 


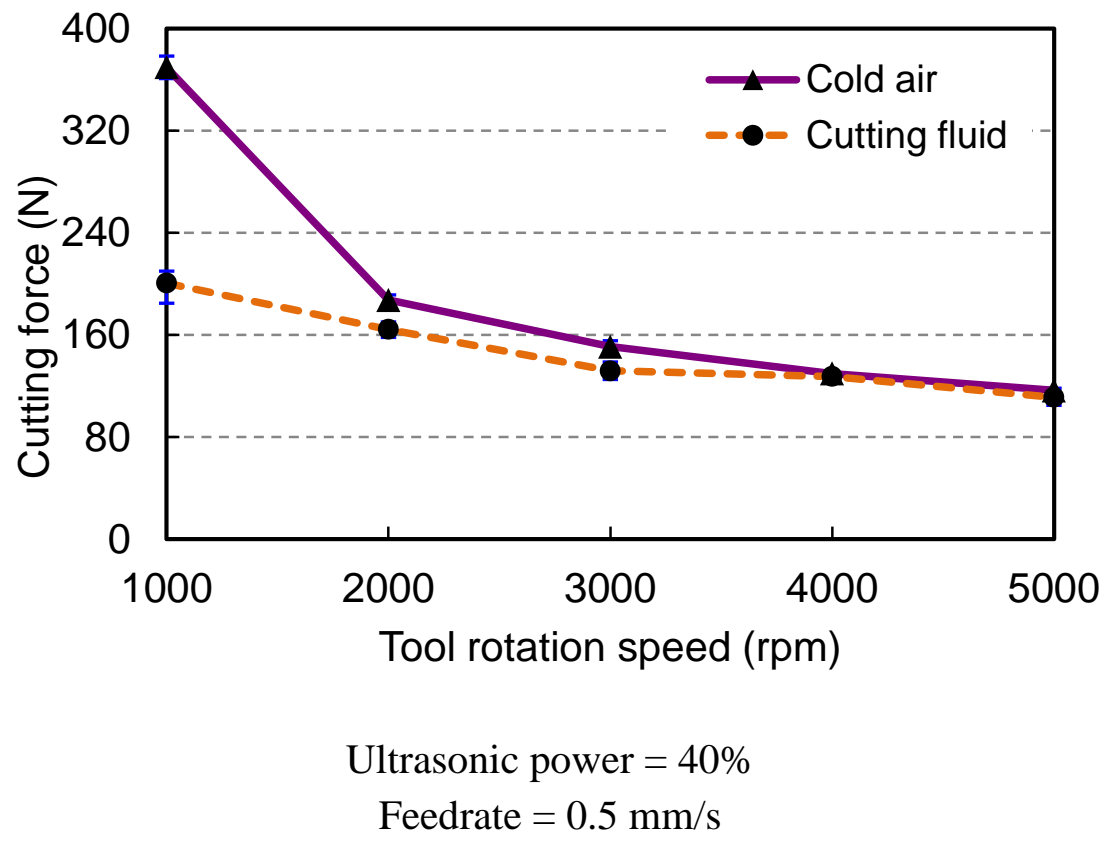

Figure 3 Comparison of cutting force under different settings of tool rotation speed. 


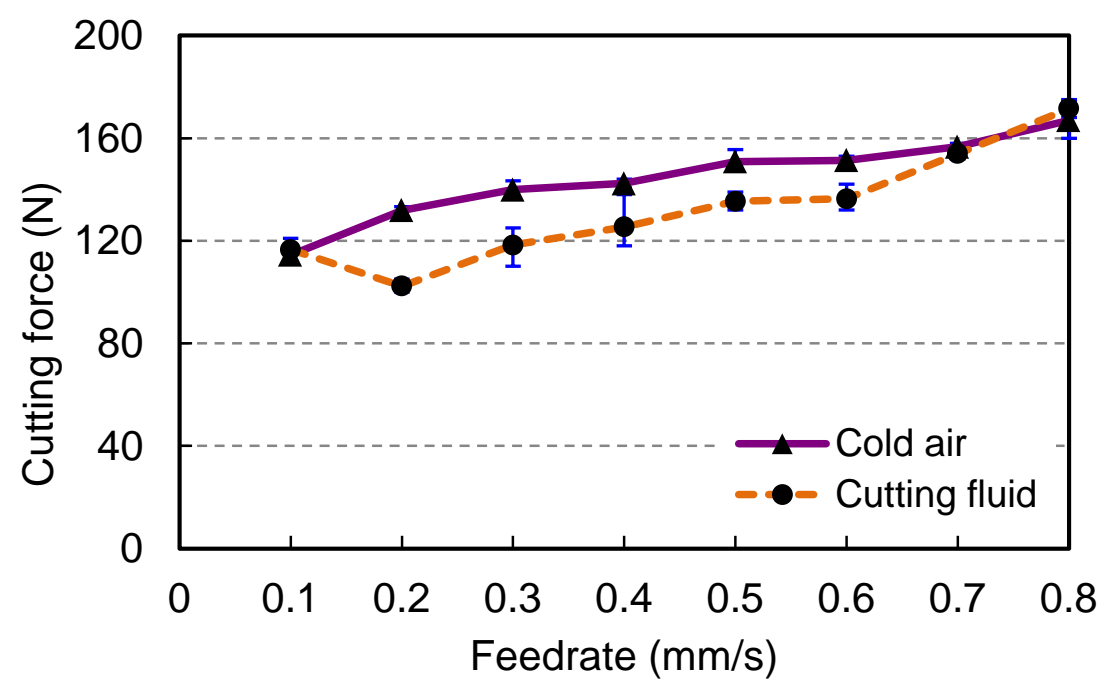

Ultrasonic power $=40 \%$

Tool rotation speed $=3000 \mathrm{rpm}$

Figure 4 Comparison of cutting force under different settings of feedrate. 


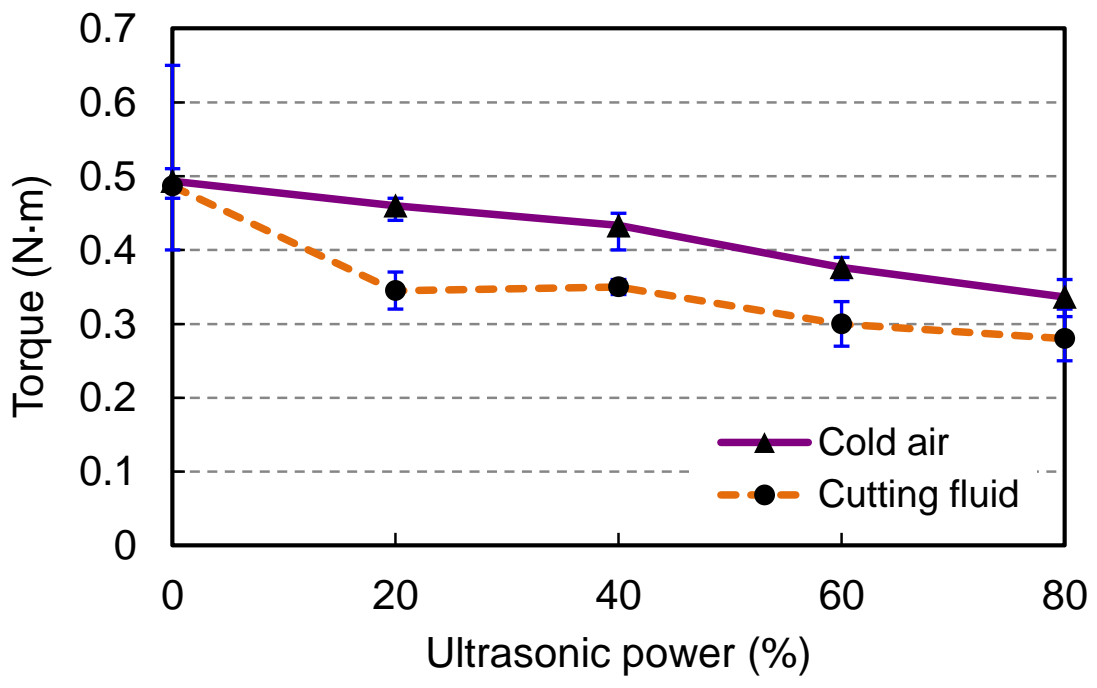

Tool rotation speed $=3000 \mathrm{rpm}$

Feedrate $=0.5 \mathrm{~mm} / \mathrm{s}$

Figure 5 Comparison of torque under different settings of ultrasonic power. 


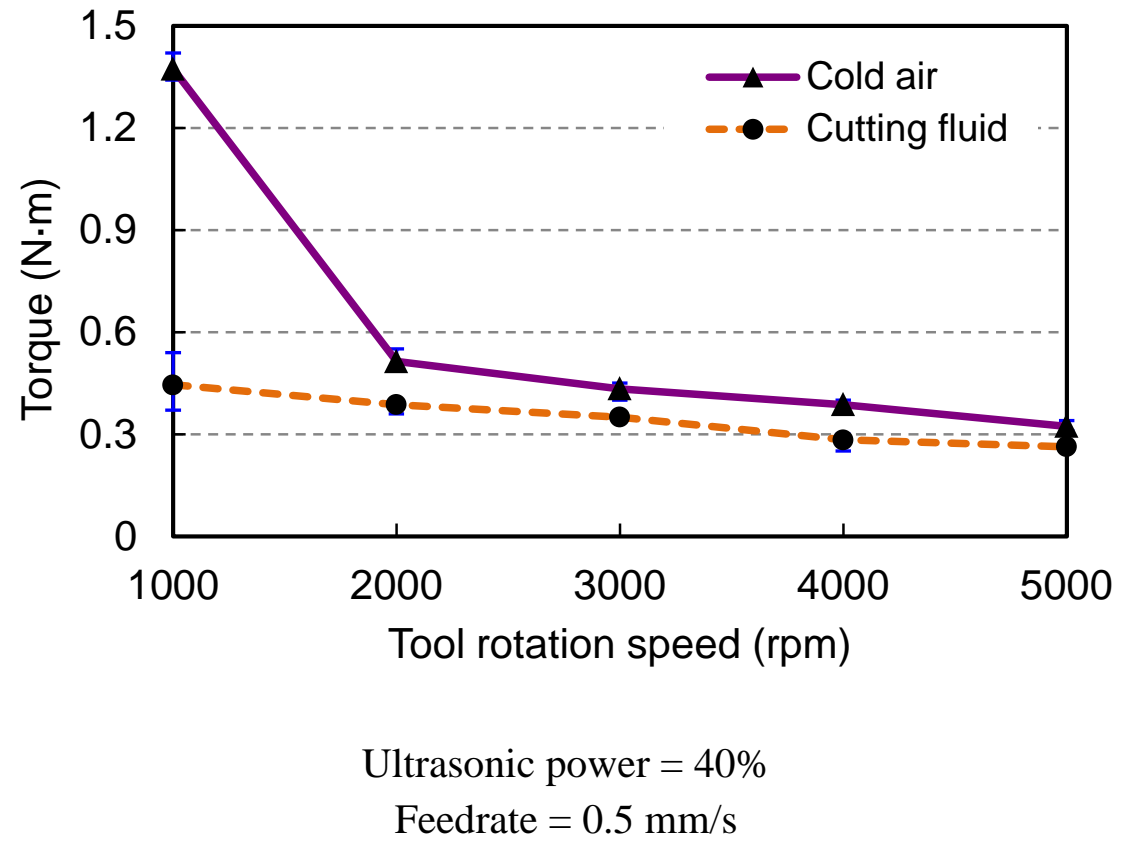

Figure 6 Comparison of torque under different settings of tool rotation speed. 


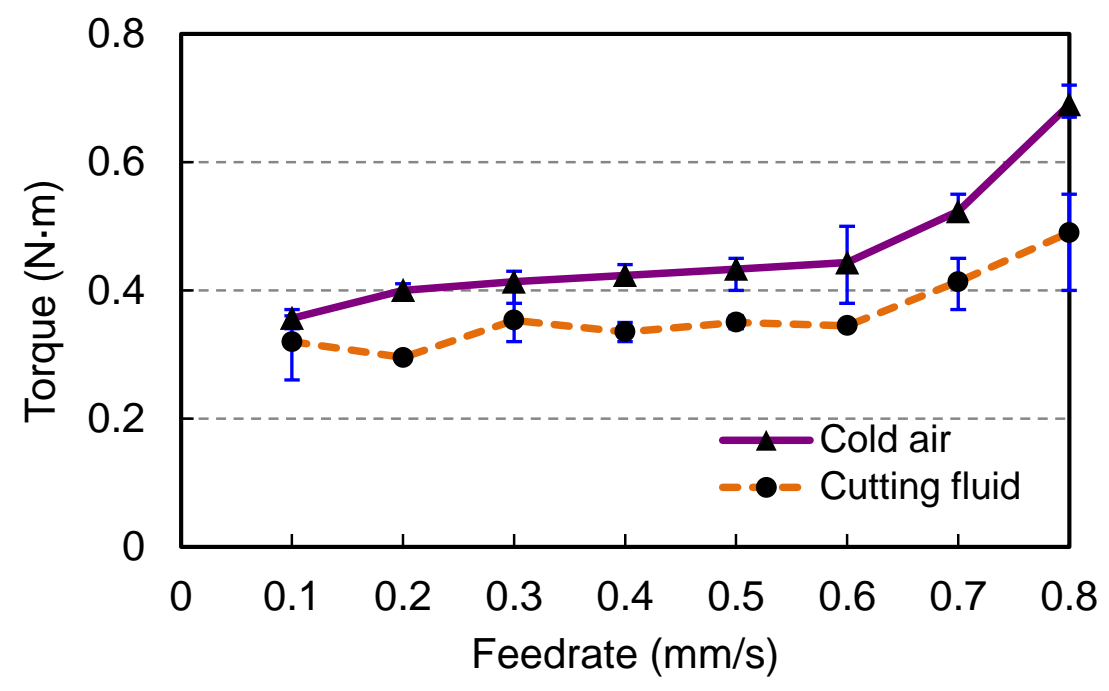

Ultrasonic power $=40 \%$

Tool rotation speed $=3000 \mathrm{rpm}$

Figure 7 Comparison of torque under different settings of feedrate. 


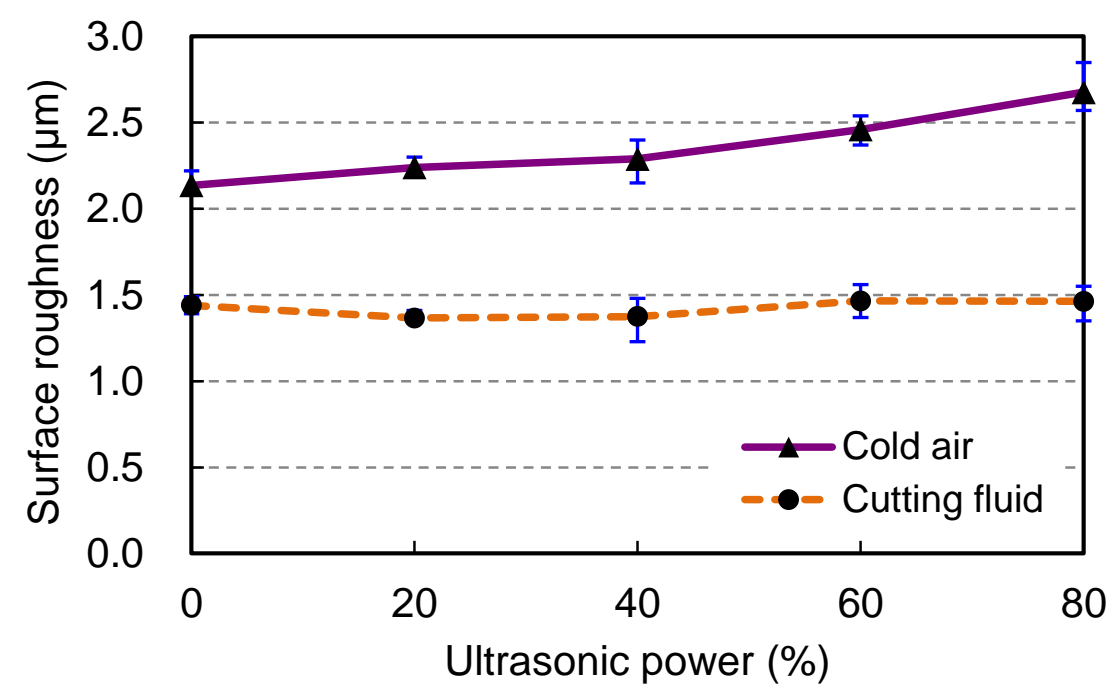

Tool rotation speed $=3000 \mathrm{rpm}$

Feedrate $=0.5 \mathrm{~mm} / \mathrm{s}$

(a) at the entrance location

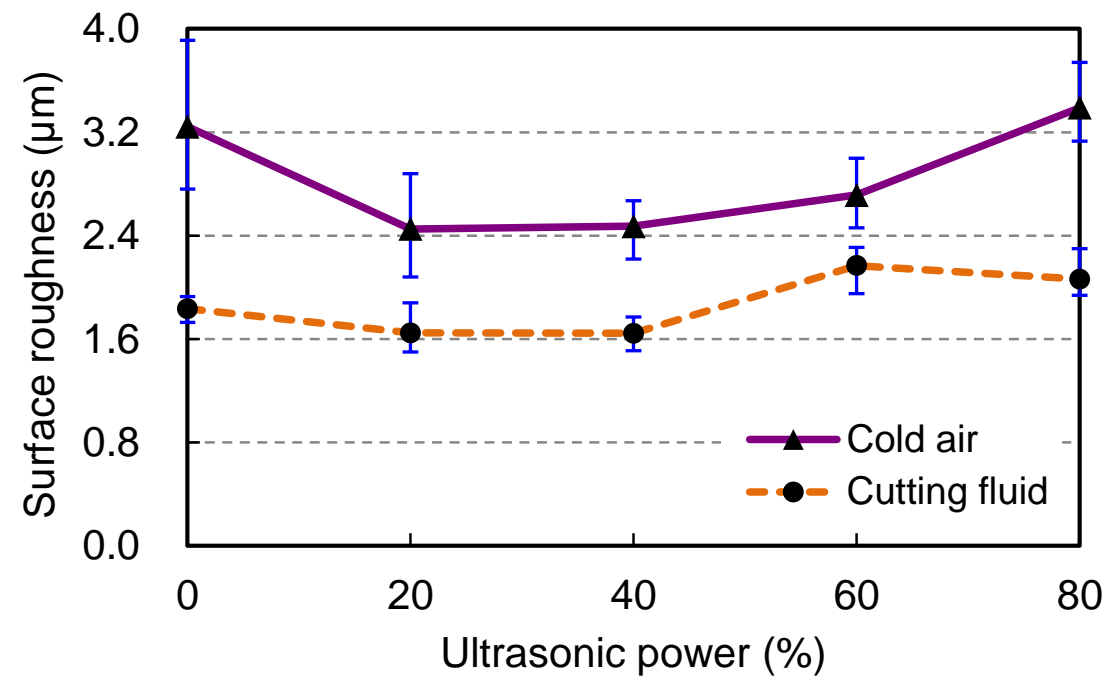

Tool rotation speed $=3000 \mathrm{rpm}$

Feedrate $=0.5 \mathrm{~mm} / \mathrm{s}$

(b) at the exit location

Figure 8 Comparison of surface roughness under different settings of ultrasonic power. 


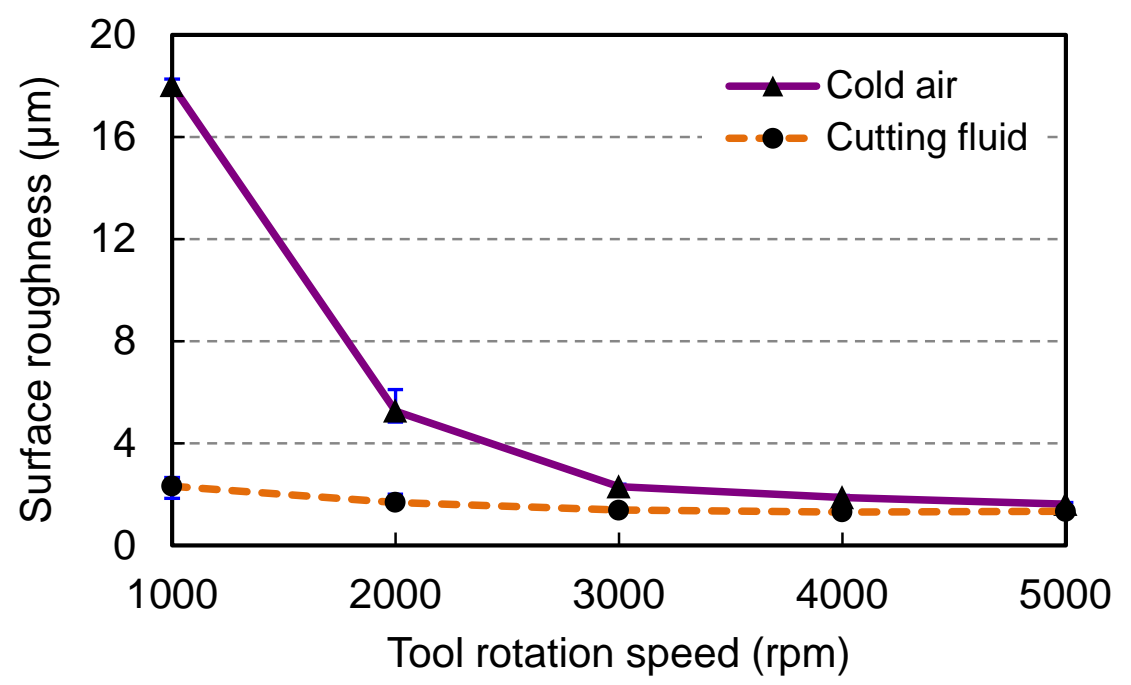

Ultrasonic power $=40 \%$

Feedrate $=0.5 \mathrm{~mm} / \mathrm{s}$

(a) at the entrance location

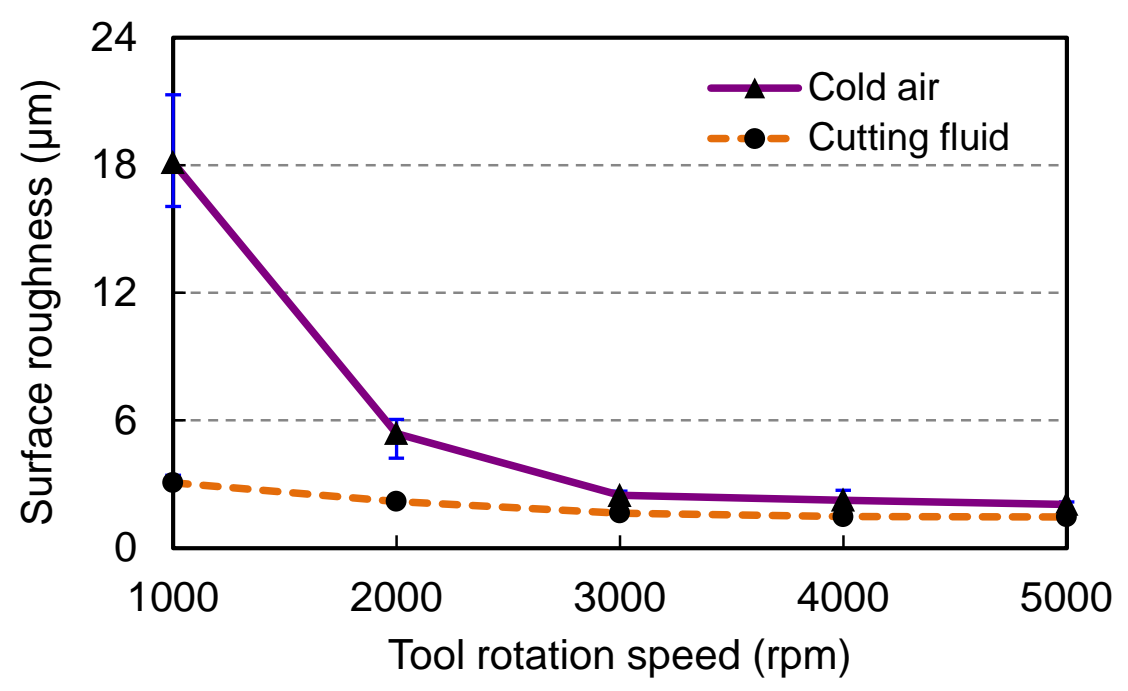

Ultrasonic power $=40 \%$

Feedrate $=0.5 \mathrm{~mm} / \mathrm{s}$

(b) at the exit location

Figure 9 Comparison of surface roughness under different settings of tool rotation speed. 


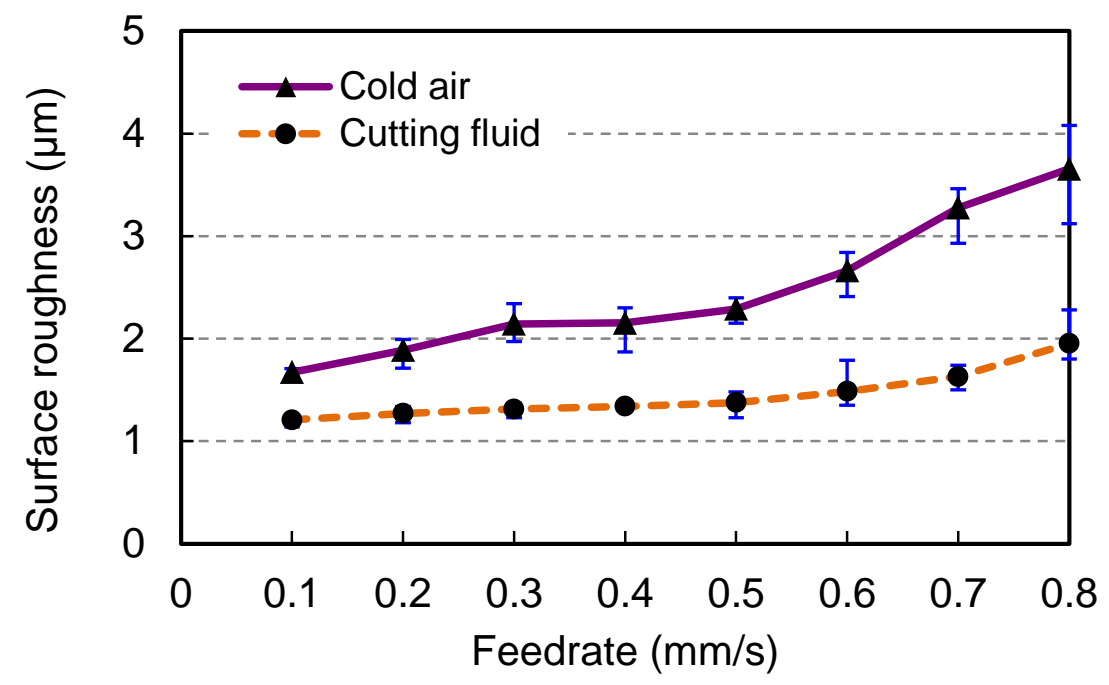

Ultrasonic power $=40 \%$

Tool rotation speed $=3000 \mathrm{rpm}$

(a) at the entrance location

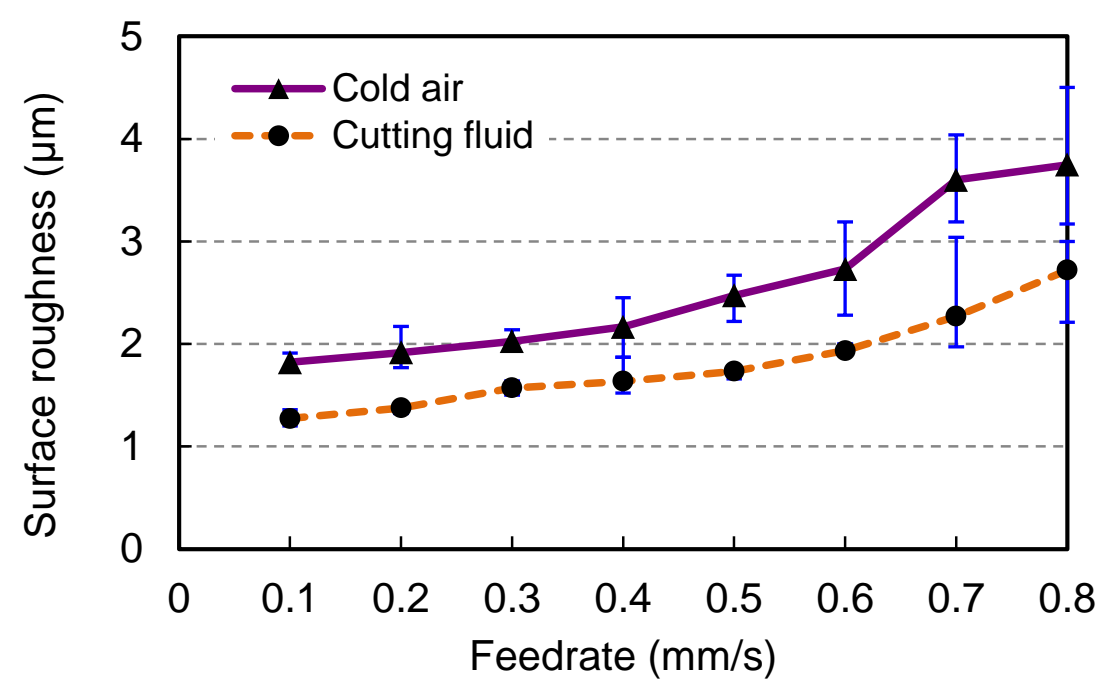

Ultrasonic power $=40 \%$

Tool rotation speed $=3000 \mathrm{rpm}$

(b) at the exit location

Figure 10 Comparison of surface roughness under different settings of feedrate. 


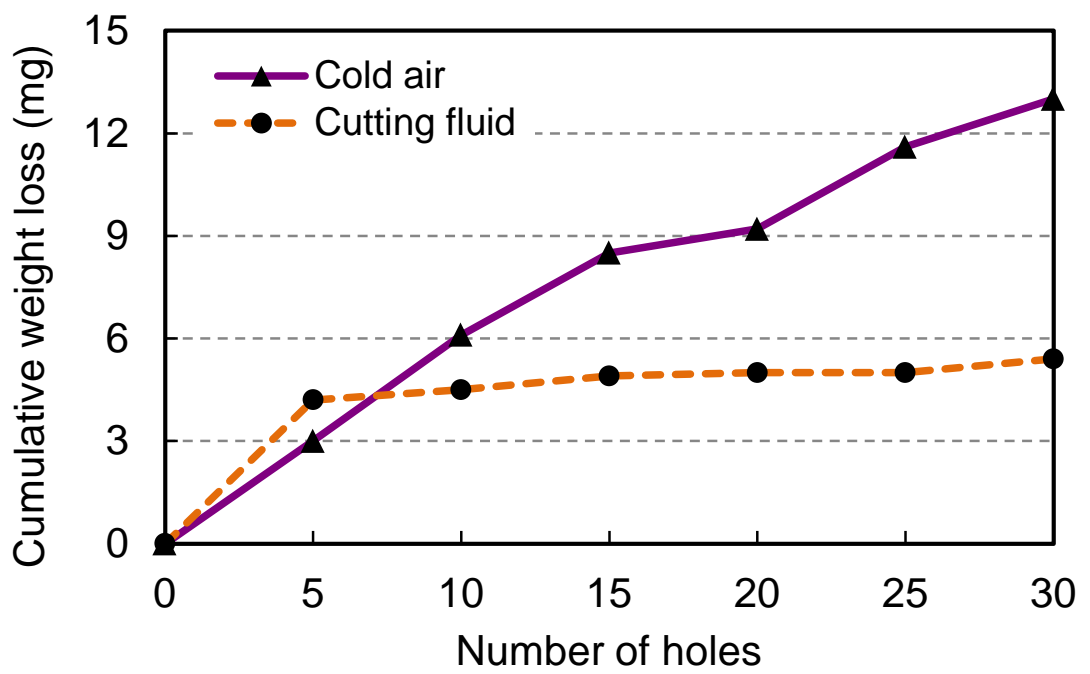

Ultrasonic power $=40 \%$;

Tool rotation speed $=3000 \mathrm{rpm}$;

Feedrate $=0.5 \mathrm{~mm} / \mathrm{s}$

Figure 11 Comparison of tool wear. 
Table 1 Workpiece material properties.

\begin{tabular}{lll}
\hline Property & Unit & Value \\
\hline Density & $\mathrm{kg} / \mathrm{m}^{3}$ & 1550 \\
Hardness (Rockwell) & $\mathrm{HRB}$ & $70-75$ \\
Elastic modulus of epoxy matrix & $\mathrm{GPa}$ & $2.06-2.15$ \\
Tensile strength of epoxy matrix & $\mathrm{MPa}$ & $80-85$ \\
Elastic modulus of carbon fiber & $\mathrm{GPa}$ & $75-80$ \\
Tensile strength of carbon fiber & $\mathrm{MPa}$ & $400-450$ \\
\hline
\end{tabular}


Table 2 Input variables and their values.

\begin{tabular}{ll}
\hline Variable & \multicolumn{1}{c}{ Value } \\
\hline Ultrasonic power (\%) & $0 ; 20 ; 40 ; 60 ; 80$ \\
Tool rotation speed (rpm) & $1000 ; 2000 ; 3000 ; 4000 ; 5000$ \\
Feedrate (mm/s) & $0.1 ; 0.2 ; 0.3 ; 0.4 ; 0.5 ; 0.6 ; 0.7 ; 0.8$ \\
Cold air pressure (psi) & 40 \\
Cold air flow rate (lpm) & 1.5 \\
Cold air temperature $\left({ }^{\circ} \mathrm{C}\right)$ & $-3 \pm 2$ \\
\hline
\end{tabular}


Table 3 Effects of ultrasonic power on burning ratio using cold air.

\begin{tabular}{cccccc}
\hline \multirow{2}{*}{ Feedrate (mm/s) } & \multicolumn{5}{c}{ Ultrasonic power (\%) } \\
& 0 & 20 & 40 & 60 & 80 \\
\hline 0.1 & 0 & 0 & 0 & 0 & $10 \%$ \\
0.5 & 0 & 0 & 0 & 0 & 0 \\
\hline
\end{tabular}

*Tool rotation speed $=3000 \mathrm{rpm}$. 
Table 4 Effects of tool rotation speed on burning ratio using cold air.

\begin{tabular}{cccccc}
\hline \multirow{2}{*}{ Feedrate (mm/s) } & \multicolumn{5}{c}{ Tool rotation speed (rpm) } \\
& 1000 & 2000 & 3000 & 4000 & 5000 \\
\hline 0.1 & 0 & 0 & 0 & 0 & 0 \\
0.5 & $90 \%$ & $50 \%$ & 0 & 0 & 0 \\
\hline
\end{tabular}

*Ultrasonic power $=40 \%$. 
Table 5 Effects of feedrate on burning ratio using cold air.

\begin{tabular}{cccccccc}
\hline \multicolumn{7}{c}{ Feedrate $(\mathrm{mm} / \mathrm{s})$} \\
0.1 & 0.2 & 0.3 & 0.4 & 0.5 & 0.6 & 0.7 & 0.8 \\
\hline 0 & 0 & 0 & 0 & 0 & 0 & $10 \%$ & $20 \%$ \\
\hline
\end{tabular}

*Ultrasonic power $=40 \%$; Tool rotation speed $=3000 \mathrm{rpm}$. 